\title{
Factors Affecting Uptake of Human Papilloma Virus (HPV) Vaccination among in- School Adolescent Girls in Wakiso District, Central Uganda.
}

\author{
Journal of Obstetrics and Gynecology@SJHR-Africa \\ Zaitune Nanyunjaa,1,2 \\ a Faculty of Health Sciences, Uganda Martyrs University, \\ Nkozi, Uganda
}

\begin{abstract}
Background:
Since 2008, the Human Papillomavirus (HPV) vaccination has been routinely recommended for preadolescents and adolescent girls in Uganda. The introduction of HPV vaccines represents a step forward in the primary prevention of cervical cancer and other HPV-related malignancies. This study examines the factors affecting the uptake of HPV vaccination among in-school adolescent girls in Wakiso district to generate information that can be used to improve the uptake of such critical services. Methodology:

A cross-sectional analytical study was employed. Both quantitative and qualitative data were collected concurrently. Data were collected from secondary schools in Wakiso district, selected using cluster sampling. Semi-structured self-administered questionnaires were used to collect quantitative data while data from mothers in Wakiso were collected using In-depth interviews through group dialogue sessions. Data were analyzed using SPSS 16.0; characteristics of the sample were summarized by descriptive statistics

Results:

The findings indicate the HPV vaccination uptake rate as low as 9.2\% among the In-school adolescent girls in the Wakiso district. $68.5 \%$ belonged to the age group 16-19 (older adolescents). $91.2 \%$ had already had vaginal sex and $90.4 \%$ had ever had any STI. In the bivariate analyses, five factors were presented to be statistically significant with a $\mathrm{P}<0.05$, implying that these factors were associated with HPV vaccination. They included the occupation of the caretaker, education level of the caretaker, perceived susceptibility to HPV infections and cervical cancer, perceived benefits of HPV vaccination, and knowledge attributes regarding HPV and HPV infections.

Conclusion:

The Ministry of the health of Uganda and partners should offer ample orientation and training to all health workers and encourage them to disseminate information on HPV vaccination to all eligible adolescents and their caretakers in Wakiso district central Uganda.
\end{abstract}

\section{Background:}

\section{Background:}

\footnotetext{
${ }^{1}$ Corresponding author.

2E-mail: nanyunjazai@gmail.com
} 
Human Papilloma Virus (HPV) vaccines are vaccines that prevent women from infection by certain types of HPV. The HPV vaccines can prevent more than 4 million deaths in women in low and middle-income countries with up to $70 \%$ coverage rate in the next decade (Hussain, 2016).

Globally, cervical cancer accounts for about a quarter of the million deaths of women annually of which 85\% occur in developing countries (LaVigne et al., 2017). In Uganda, about 3915 women are diagnosed with cervical cancer and 2275 (58\%) die from the malignancy each year (Nakisige et al., 2017). The human papillomavirus (HPV) is sexually transmitted and has been conclusively linked to cervical cancer and genital warts (Braaten et al., 2008). About 50-80\% of sexually active women are exposed to at least one HPV type during their lifetime ( Makwe et al., 2012). The incidence of HPV infection occurs in most populations within 5-10 years of the first sexual experience and prevalence rates are seen in women aged 20-24 years (CDC, 2014). The transmission of HPV infection is influenced by age at sexual debut, multi-parity, several sexual partners, and acquisition of new partners with other sexually transmitted infections (STIs) also known to be risk factors for HPV (Read et al., 2010).

The Advisory Committee on Immunization Practices (ACIP) recommends the administration of HPV vaccine at age 11 or 12 years for routine vaccination and can also be at age 9 , it further recommends vaccination for females aged 13 to 26 years and males 13 to 21 not adequately vaccinated (Small et al., 2011). Many professional organizations followed ACIP recommendations including the American Medical Associations, the American Academy of Pediatrics, the American College of Obstetricians and Gynecologists, the American Academy of Family Physicians, the Association of Women's Health, the society of Adolescent Medicine, as well as the American Cancer Society, in supporting routine HPV vaccination for females (Small, 2011).

Since 2006, HPV vaccines have been available in some countries to protect against the virus among adolescent girls and women (Kessels, 2012).

To achieve optimal HPV vaccine uptake cost-effectively, countries have delivered these vaccines to adolescents through schools, health facilities, and community outreach (Lamontagne et al., 2011). In sub-Saharan Africa, while some countries have also opted to combine a school-based approach with one other strategy to broaden vaccine reach especially for girls who are not enrolled in school. Many parents of African countries have poorer uptake of childhood immunizations (Mupandawana et al., 2016). Many Sub-Saharan African young women with sexually transmitted infections receive advice on prevention and treatment of these STIs through health providers and appear to know the importance of HPV vaccination but many have failed to take their daughters for vaccination.

Wamai et al., (2012) assert that all parents of adolescent girls need to be informed on how HPV is transmitted and the efficacy of the HPV vaccine in preventing cervical cancer and other related cancers or STIs caused due to its presence in the body.

In 2008, Uganda carried out a demonstration project for HPV vaccination in Nakasongola and Ibanda districts and the project ended with impressive results (Banura et al., 2012). Later in 2012, twelve additional districts were piloted to make a total of fourteen, which since then have been implementing the HPV vaccination program supported by the Global Alliance for Vaccines and Immunization (GAVI), World Health Organization, UNICEF, and MSD. These health-promoting programs should run in conjunction with primary protection, through vaccination against HPV and at a later stage, secondary protection through screening of the population for HPV related cancers. In Uganda, a national HPV vaccination program for the prevention of cervical cancer was initiated and is currently ongoing; however, efforts by the Ministry of Health in Uganda have been uncoordinated with limited success (Nakisige, 2017).

In all countries, the success of vaccination programs is dependent on the support of the public and healthcare professionals. Whilst public acceptance is dependent on multiple factors, it has repeatedly been shown that recommendations by health professionals, particularly clinicians, are paramount to vaccine uptake. However, a proportion of clinicians still have significant reservations about promoting HPV vaccination, particularly for younger age groups (Hopkins et al., 2013). According to Okoth et al., (2016), the emphasis was geared towards encouraging parents to have their children immunized against HPV as failure to do so pose a risk of developing cervical cancer, caused by the HPV which is transmitted through sexual contact with an infected person 
This study aimed to investigate factors related to HPV vaccine uptake among in-school adolescent girls in Wakiso district.

The study was conducted in Wakiso district, located in the Central region of Uganda. It surrounds Kampala district, the country's capital city, and borders Mukono district in the East, Nakaseke district and Luweero district to the North, Kalangala district in Lake Victoria to the South, Mpigi district to the southwest, and Mityana district to the Northwest. Wakiso district has got two counties, 17 sub-counties, 135 parishes, and 2 municipalities. The counties are; Kyaddondo county and Busiro county with a total area of 2,704square kilometers (1,044 sq mi).

Geographically, the study was conducted in Wakiso district consisting of 17 sub-counties including Makindye-Ssabagabo, Nsangi, Sisa, Katabi, Busukuma, Gombe, Nabweru, Kakiri, Kira, Namayumba, Kasanje, Masulita, Nangabo, Wakiso TC, Division A, and Division B.

The district also consists of 8 Parliamentary Constituencies including, Kira municipality constituency, Entebbe municipality constituency, Makindye-ssabagabo municipality constituency, Nansana municipality constituency, Kyadondo county east constituency, Busiro county south constituency, Busiro county north constituency, and Busiro county east constituency.

\section{METHODOLOGY}

\section{Study Design}

The study employed a cross-sectional analytical design that used quantitative and qualitative methods of data collection and analysis. The study had descriptive as well analytical components which enabled understanding factors of uptake.

It was cross-sectional research because it made comparisons at a single point in time as data were collected at a defined time. This approach uses several methods of collecting data, highlighting the benefits of looking at the different variables in their natural setting as they interrelate with one another. The design allowed the researcher to generate descriptive data that were used in measuring the correlation between variables. Although the study was descriptive, statistics were used to describe the relationships between the variables making it analytical.

\section{Study Area}

This study was carried out in Wakiso District, Central Uganda. Wakiso district was purposively selected for this study because it is one of the additional districts where the HPV vaccination campaign is currently operating among others in Uganda. Secondly, the Wakiso district has a cosmopolitan population due to its proximity to the country's capital city. It is the largest district in Uganda with a total population 1,997,418 of which 949,035 (47.5\%) are males and 1,048,383 (52.5\%) females recorded in the 2014 census (NPHC, 2014). There is also document evidence that HPV vaccine uptake is low (Snidal, 2018). The study was carried out in schools in the Wakiso district.

\section{Study population}

A population can be defined as the entire group or events or things that a researcher wishes to investigate Sekaran, (2003). According to the National Population and Housing Census (NPHC) (2014), the district has a total number of adolescents aged 10-19 years totaling 446195, of which 119380 are males and 246815 are females. Out of that total population, persons aged 13-19 years attending secondary school education are 128,893 (48.9\%) of which 56,864 (50.3\%) are males and 72,029 (47.9\%) females (NPHC, 2014 - Area-specific profile Wakiso district).

The study population comprised of 72,029 persons (adolescent girls) aged 13-19 attending secondary school education in Wakiso district (Area-specific profile Wakiso district-NHPC, 2014). It is from this target population that the sample size was determined.

\section{Sampling Procedures}

Sample Size

A total number of 382 respondents (adolescent girls) aged 13-19 years in secondary schools of Wakiso district were estimated for the study. The study utilized a sample size determination table as recommended 
by Morgan and Krejcie (1970). Data were also collected from mothers as caretakers of the adolescent girls residing in Wakiso District. A total of 46 mothers were reached.

\section{Sampling Techniques}

To obtain the respondents, both probability and non-probability techniques were used. The study used Bennett's formula to calculate the number of clusters needed. Using Bennett's formula for cluster sampling, 4 clusters (municipality constituencies) were drawn from the overall total sample size of 382 respondents obtained from Krejcie \& Morgan (1970) technique of sample size determination. Using the 2014 Uganda population and housing census, we obtained a ratio of adolescents to mothers as 6:4 and we used it to get the number of adolescent and adult mothers we needed in the study. With a total of 382 adolescents, we needed 46 adults that would be interviewed.

A list of municipality constituencies and their population sizes was obtained from the Uganda Bureau of Statistics (UBOS). The selected municipality constituencies were visited to draw a sampling frame. During this visit, contact with the municipality constituency leaders and identifying guides for the survey was made. Before data collection, letters were sent to chairpersons of the local councils with details of the date of visit and a request for cooperation. Local area council chairpersons were the main point of entry in the field. A mix of multi-stage and cluster sampling techniques was applied.

Using a multi-stage sampling method, 50 percent of the municipality constituencies were randomly selected from the 8 parliamentary municipality constituencies in the Wakiso district. Thereafter, 50 percent of the sub-counties were randomly selected from each of the selected municipality constituency. Several parishes that were proportionate to the size of the sub-county were selected using simple random sampling from each sub-county. In each cluster (sub-county) we targeted to get at least 96 respondents (adolescent girls in school). In each selected sub-county we constructed two sampling frames, one comprising female adolescents 13-19 and the other adult women 20 and above. Those who qualified to be on the sampling frames were first-time mothers with a child/ children more than five years of age. About 12 mothers representing 12 eligible households were randomly selected from each of the 4 sub-counties using a simple random sampling technique by using a table of random numbers.

At the sub-county level, schools were randomly selected. On average two to three schools from each sub-county were selected, making a total of 10 schools. Out of the selected schools, 7/10(58\%) came from urban slums and 3/10(42\%) from rural settings. At the school level the selection of the respondents was based on stratification into upper (senior 5 to 6 ) and lower (senior 1 to 4 ) respectively. Two classes from each stratum were randomly selected. Within the selected classes, registers were obtained from which systematic sampling was done to select the children. In each of the two classes, nine or 10 students were randomly selected, giving a total of approximately 19 students investigated in each stratum per school. Therefore 38 respondents (adolescent girls) were selected from each school.

The study also used purposive sampling techniques to cater to the mothers of adolescent girls. I conducted an in-depth interview with mothers at a time in the selected sub-counties in the Wakiso district; mothers were interviewed until I reached the saturation point. A total of 46 mothers were interviewed. These were obtained from the catchment area of the selected sub-counties from which the study was conducted; hence the sample size was reached when the saturation point was recognized.

\section{Collection Methods}

This study used structured interviews to collect the data that was required. A structured interview questionnaire was used which comprised of predetermined responses in a multiple-choice format. This type of data collection method was used because of the ease with which each interview can be done if questions are close-ended, and because of the relatively little time that is required for conducting a structured interview, which is of an advantage especially if large sample sizes are required.

On the other hand with mothers, the In-depth interviews were conducted using pre-tested and translated In-depth interview guides. With the help of women councilors, In-depth interviews were held in homesteads and few facilities, and precautions were taken to minimize external disruptions. Each In-depth interview lasted for approximately 40mins. The In-depth interviews explored the initial reactions of the community to the introduction of HPV vaccination, community members' understanding of HPV vaccina- 
Table 1. shows the school codes from the different sub-county, and the number selected.

\begin{tabular}{|c|c|c|c|c|}
\hline MUNICIPALITY CONSTITUENCY & SUB-COUNTY & $\mathrm{n} / \mathrm{a}$ & SCHOOL CODES & NUMBER SELECTED \\
\hline \multirow{3}{*}{$\begin{array}{l}\text { Makindye-Ssabagabo Municipality } \\
\text { constituency }\end{array}$} & \multirow{3}{*}{$\begin{array}{l}\text { Makindye- } \\
\text { ssabagabo }\end{array}$} & 1 & MS-1 & \multirow{3}{*}{114 respondents } \\
\hline & & 2 & MS-2 & \\
\hline & & 3 & MS-3 & \\
\hline \multirow{2}{*}{ Busiro county south constituency } & \multirow{2}{*}{ Katabi } & 4 & $\mathrm{~K}-1$ & \multirow{2}{*}{76 respondents } \\
\hline & & 5 & $\mathrm{~K}-2$ & \\
\hline \multirow{3}{*}{$\begin{array}{l}\text { Entebbe Municipality } \\
\text { constituency }\end{array}$} & \multirow{3}{*}{ Division A/B } & 6 & $\mathrm{E}-1$ & \multirow{3}{*}{76 respondents } \\
\hline & & 7 & $\mathrm{E}-2$ & \\
\hline & & 8 & $\mathrm{~N}-1$ & \\
\hline \multirow[t]{2}{*}{ Busiro county east constituency } & Nsangi & 9 & $\mathrm{~N}-2$ & 114respondents \\
\hline & & 10 & $N-3$ & \\
\hline TOTAL & & & & 380 \\
\hline
\end{tabular}

tion benefits, fears, complaints, and rumors about the vaccination. The In-depth interview also explored the mothers' willingness to have their daughters vaccinated against HPV.

\section{Data Collection Tools}

In this research study, semi-structured questionnaires were used to collect quantitative data among adolescents attending secondary school education. The instrument was adopted from the study of Schaefer (2010), whose questionnaire used an HPV and HPV vaccine knowledge assessment tool and a comprehensive health belief model assessment. While the original validated questionnaire was written for women, the questions used for the study were modified and updated to assess the current HPV vaccine available for adolescent girls.

To reduce data loss, collected data were double-checked for completeness and accuracy, and incomplete as well as inaccurate data was corrected in real-time.

\section{Study Variables and Indicators}

All variables for this study were extracted from the study objectives as indicated in chapter one.

The dependent variable

The dependent variable was the uptake of HPV vaccination among in-school adolescent girls. The study assessed the outcome variable (uptake of the vaccine) by asking respondents questions that described their vaccination status.

\section{HPV Vaccination Status}

The primary outcome of the study was the uptake of HPV vaccination and was measured by one item. Participants were asked to indicate whether they had ever taken HPV vaccination, with the variable coded as $1=$ yes and $0=$ no. However, other questions were included in the questionnaire to cross-check the responses selected for the primary outcome. These questions included the number of doses received if you if option one 'yes' was selected and followed by "Which of the following best describes your current situation?" followed by the choices (a) Have completed the series of 3 shots for the HPV vaccine, (b) Have you started, but not completed, the series of 3 shots for the HPV vaccine, (c) Have scheduled an appointment with my doctor to receive the HPV vaccine, (d) Have not received the HPV vaccine or scheduled an appointment to receive the HPV vaccine.

\section{Independent Variable}

\section{(a) Individual Factors \\ Demographics}

In the questionnaires this information was obtained by asking for the participants' age, ethnicity, stay with parents, caregivers' education level, types of family, and relationship status.

\section{HPV \& HPV Vaccine Awareness}

Basic HPV and HPV vaccine awareness questions were asked by participants responding with "(a) Yes, (b) No" to the following questions: "Before taking this survey, had you ever heard of HPV (human 
papillomavirus)?"; “Before taking this survey, had you ever heard of the HPV vaccine (Gardasil ${ }^{\circledR}$, Cervarix $\left.^{\circledR}\right)$ ?"; "If yes, where have you heard about the HPV vaccine?" (Health care provider, friend, family member, Television or radio, Internet, Newspaper or magazine, at school, other (specify), I don't remember).

\section{HPV Knowledge}

Knowledge about HPV and the HPV vaccine was assessed with ten items. There are five multiple answers including items such as, "HPV increases the risk of Cervical cancer," There are also four true/false statements including items such as, "HPV affects only women" and "HPV can occur without symptoms." For scoring purposes, each possible response equaled one point. The items were classified into two grades; not knowledgeable (NO) and knowledgeable (YES)

\section{Measuring Attitudes}

The following sections of the instrument assessed participants' attitudes towards HPV and the HPV vaccine according to the constructs of the health belief model (perceived susceptibility, perceived severity, perceived benefits, perceived barriers, and cues to action).

\section{Perceived Susceptibility}

Four items were used to inform participants' perceived susceptibility to HPV infection. These items include statements such as; "HPV is for people who are sexually active". The instrument also measured the participant's risk of developing HPV and HPV-related diseases if not vaccinated. These items included questions such as, "What are your chances of contracting HPV if you didn't have the HPV vaccine compared to other adolescent girls?" these items were rated on a scale of $0-100 \%$. The percentages were averaged to create a final score ranging from $0-100 \%$ where low scores $(<50 \%)$ indicated low perceived susceptibility and high scores (>50\%) indicated high perceived susceptibility if not vaccinated.

The questionnaire also assessed the independent variables sexual history and this was assessed by asking 2 items (a. yes b. no):

"Have you ever had (a) vaginal sex? (b) Anal sex (c) oral sex)" and "Have you ever had a sexually transmitted disease?"

\section{Perceived Severity}

The perceived severity measure comprised of two items that assess respondents' reactions to a potential diagnosis of HPV and concerns about potential consequences of infection. The two items include statements such as, "Cervical cancer is a serious disease" and "HPV infection is a serious health problem."

\section{Perceived Benefits}

Four items were also used to measure participants' perceived benefits of receiving the HPV vaccine. The items include statements such as, "HPV vaccine is effective in preventing cervical cancer" and "HPV vaccine is effective in preventing genital warts."

\section{Perceived Barriers}

Perceived barriers were assessed by participants' responses to four items about the perceived negative aspects of the vaccine. These items refer to the difficulties to receive the vaccine and include questions such as, "HPV vaccine causes significant side effects". These items are rated on "Disagree (NO) and Agree (YES)."

\section{Cues to Action}

Cues to action refer to cause either internally or within the environment that could potentially influence health behavior. The items asked questions such as, "Have you ever known anyone who has had HPV?" and "Has a health care provider ever recommended that you receive the HPV vaccine?" These questions were rated on "Yes" and "No". The question "Have you ever known anyone who has had negative side effects from a vaccine?" is reverse coded. Low scores indicated a lower number of positive cues to action and high scores indicated a higher number of positive cues to action for receiving the HPV vaccines.

At the end of the survey, the question was posed to enable the researcher to conclude the available HPV vaccination and needs of adolescents, "After completing this survey, how interested are you in learning more about the HPV vaccine?" (a) Very interested (b) Somewhat interested (c) Not interested. 
Table 2. shows the Variables

\begin{tabular}{|c|c|c|c|c|}
\hline Objectives & Variable & Indicators & $\begin{array}{l}\text { Mea- } \\
\text { sure- } \\
\text { ment } \\
\text { Method }\end{array}$ & $\begin{array}{l}\text { Tools And } \\
\text { Sources of } \\
\text { Data }\end{array}$ \\
\hline $\begin{array}{l}\text { To describe the HPV } \\
\text { vaccination uptake } \\
\text { rate among in school } \\
\text { adolescent girls in } \\
\text { Wakiso district }\end{array}$ & HPV uptake rate & $\begin{array}{l}\text { Number of adolescents } \\
\text { being vaccinated against } \\
\text { human Papilloma virus. } \\
\text { Number of adolescents not } \\
\text { being vaccinated }\end{array}$ & $\begin{array}{l}\text { Quan- } \\
\text { tita- } \\
\text { tive }\end{array}$ & $\begin{array}{l}\text { Close ended } \\
\text { questionnaires } \\
\text { Adolescent girls } \\
\text { (380) }\end{array}$ \\
\hline $\begin{array}{l}\text { To assess individual } \\
\text { factors that are } \\
\text { related to uptake of } \\
\text { HPV vaccination }\end{array}$ & $\begin{array}{l}\text { Knowledge Perceived } \\
\text { susceptibility Perceived } \\
\text { severity Perceived } \\
\text { benefits Perceived } \\
\text { barriers Cues to action }\end{array}$ & $\begin{array}{l}\text { Number of variables } \\
\text { mentioned / selected to a } \\
\text { barrier for HPV vaccine } \\
\text { uptake }\end{array}$ & $\begin{array}{l}\text { Quan- } \\
\text { tita- } \\
\text { tive }\end{array}$ & $\begin{array}{l}\text { Questionnaire } \\
\text { Adolescent girls } \\
\text { (380) }\end{array}$ \\
\hline $\begin{array}{l}\text { To examine assess } \\
\text { community factors } \\
\text { that affect HPV } \\
\text { vaccination uptake }\end{array}$ & $\begin{array}{l}\text { Community knowledge } \\
\text { level Perceptions Access }\end{array}$ & $\begin{array}{l}\text { Number of individual who } \\
\text { are aware of HPV vaccines }\end{array}$ & $\begin{array}{l}\text { Quali- } \\
\text { tative }\end{array}$ & $\begin{array}{l}\text { In depth } \\
\text { interview guide } \\
\text { Mothers as } \\
\text { caretakers of } \\
\text { adolescent girls }\end{array}$ \\
\hline
\end{tabular}

\subsection{Community factors}

To begin with, mothers' Levels of knowledge towards HPV vaccination were assessed. This was done by assessing their Knowledge level about the availability of information about the prevention of HPV infections particularly cervical cancer. The method that was used to obtain data from respondents was a narrative qualitative method. The tool of data collection was an in-depth interview.

\section{The Variable Table}

\section{Training of research assistants}

\section{Quality Control}

Four research assistants were recruited and trained for a day on issues about HPV, participant handling skills such as interviewing skills, content, and meaning of questions, correct recording of responses, and orientation to study objectives and procedures. The training also covered ethical considerations when handling participants, especially confidentiality of responses. These research assistants were recruited to help in the data collection process because being a community-based study, and given the time constraints, the researcher needed to get some more personnel to enable her to cover more ground in the field.

\section{Pretest}

Pre-testing of an instrument was done to determine its feasibility and validity (Brink \& Wood, 1998). In this present study, the researcher pre-tested the questionnaire before data collection to enhance its validity. The pretest was done to determine the comprehensibility of the questions, the ability of the questions to elicit the required data and to detect any ambiguity in the questions.

\section{Reliability}

Reliability of data refers to whether repeating the same measurement under similar conditions yields the same results (Kumar 1990). The reliability of the questionnaires was improved through pretesting of pilot samples from the field which enabled the rephrasing of some questions.

Validity refers to the appropriateness of the instrument or validity is the extent to which research results can be accurately interpreted and generalized to other populations whereas Reliability is defined as the dependability in the context of measuring the instrument. 
To establish validity, mini in-depth interview was conducted using mothers of adolescent girls to evaluate the relevance of each item in the guides to the research objectives and rate each item using a four-point scale; that is,

- Very relevant $=4$

- Quite relevant $=3$

- Somewhat relevant = 2

- Not relevant $=1$.

Validity was determined using the content validity index (C.V.I) = items rated 3or 4 by both participate divided by the total number of items in the questionnaire (Oso \& Onen, 2009). To ensure reliability, the draft copies of the instruments were pre-tested at a selected site in similar settings as well as discussing with the research supervisor and other members.

\section{Data Analysis and Presentation of the Findings}

The data analysis exercise started with field editing to check the appropriateness, consistency, and accuracy of the information provided by respondents. This exercise made it possible to contact some respondents afresh when it became necessary for clarification of certain issues and some also to complete certain questions that were left with no answers. Serial numbers were then assigned to the individual edited questionnaires for easy identification during the coding process and rechecking of information on the questionnaire during the data entry exercise. The computer software Statistical Package for Social Scientists (SPSS) version 16 at 95\% confidence interval was used to analyze the quantitative data. This is because SPSS is the most widely used statistical Software in the Social Sciences. This package provides users with a substantial increase in the ease and flexibility with which they can approach their day-to-day use of the computer to generate frequencies and percentages for easy interpretation. Frequency tables were used to present data. Numerical data were summarized into descriptive statistics where frequency and percentage were used for socio-demographic characteristics. Cross tabulation was used to show a pattern on the uptake of HPV vaccination and knowledge, attitude, and personal/socio-demographic factors that may influence uptake.

To further establish the actual variations in uptake of HPV vaccines by individual characteristics, crosstabulations were run between the significant characteristics and the dependent variable (uptake). This enabled the researcher to find out which exact proportion of adolescents took HPV vaccination, and which proportion did not. In all analyses, a 95\% confidence interval was used with associations of p-values of less than $0.05(p<0.05)$ was considered statistically significant.

Qualitative data from mothers of adolescent girls, data obtained by the user from in depth-interview guide was analyzed qualitatively whereby the information recorded was read several times, responses were sorted and grouped into themes. The researcher thereafter evaluated and analyzed the adequacy of information in answering the research questions through identifying categories and parameters that emerge in the responses then used quotations.

\section{Ethical Consideration}

\section{Permissions}

Before going into the field to collect data, the researcher first obtained an introductory letter from the Faculty of Health Sciences, Uganda Martyrs University through Uganda Martyr's university ethical review committee. Authorization was then obtained from the District Health Officer (DHO), Wakiso District, and local leaders of the selected sub-counties that are the local council leaders (LC 3).

\section{Informed Consent}

Informed consent of the study participants was sought before data collection by verbal consent in both English and Luganda. The objectives of the study were discussed with participants.

The participants 'were told whether there was no incentive but the study had benefits to the community especially for young adolescent girls and it is riskless and that they had full right to discontinue the questionnaire at any time during the session. The information obtained from the participants was kept with the utmost confidentiality. The names of the participants were not included in the questionnaire but 
rather unique codes were considered. This was well reflected in the questionnaire interview guide that was used as a data collection tool.

A possible limitation of the questionnaire method used is that respondents may tend to answer "yes" to questions despite being unsure or not knowing. According to Sudman et al., (1982), respondents may for instance answer "yes" if they feel that they "should" know the answer to the question, and they do not want to reveal that they are not up to date on current events or knowledge ("yeah-saying"). This problem is particularly relevant for the yes/no questions.

\section{DATA ANALYSIS AND PRESENTATION OF RESULTS}

\section{Introduction}

Chapter four focuses on the presentation and discussion of data according to the research objectives and variables. The presentation follows the study objectives, that is to say, to determine the HPV vaccination uptake rate among in-school adolescent girls in Wakiso district, assess individual factors that affect HPV vaccination uptake among in-school adolescent girls in Wakiso district, and to examine community factors that affect HPV vaccination uptake.

The data collected were subjected to analytical software known as Statistical Package for Social Scientists (SPSS) version 16. The findings were arrived at through analysis and interpreting of the data that were collected from the field. Therefore, the findings are presented in chronological order as per research objectives but first respondents' characteristics.

In this study, 380 questionnaires were distributed, and responses were received from10 selected secondary schools, from 4 sample clusters obtained by cluster random sampling making up a response rate of $100 \%$. Additionally, interviews were conducted with selected respondents of mothers, and a total of 46 respondents were interviewed.

\section{Social Demographic information of the Respondent}

Social demographic information included; age, ethnicity, religion, the person the respondents are living with, education level of the caregiver, occupation of the caregiver, current relationship status, and the nature of family the respondents are coming from.

\subsection{Social Demographics of the Respondents}

\section{Source: Field information (2018)}

The study sought to establish respondents' demographic characteristics to capture the representation and gain knowledge of the respondents' social setting. In this regard, the above table 3 presents age, ethnicity, religion, type of family, household arrangement, type of relationship of the respondent (adolescent girl) and the level of education, occupation of their caregivers among others.

According to the results indicated in Table 3, the majority of the respondents $224 / 380$ (58.9\%) were older adolescents aged $16-19$ years, $48 \%$ of the adolescents in the study lived with both parents and more than half a sample were not in any relationship.

The research findings revealed that 182/380 (48\%) of the respondents' caregivers had acquired secondary education, while other respondents $48(13 \%)$ did not know their caregiver's level of education. And yet, the question of education level is very important in this study since it has a significant bearing on one's ability to comprehend vaccination services as well as making sound decisions regarding one's health behaviours. A big percentage of 40\% (150/380) of the respondents' caregivers were business people and the majority of the respondents (57.1\%) came from nuclear families.

HPV Vaccination Uptake Rate among In-School Adolescents.

\section{Uptake of HPV Vaccination among in-school adolescent girls}


Table 3. Social Demographics of the Respondents

\begin{tabular}{|c|c|c|c|}
\hline Category & Attributes & Frequency & $\begin{array}{l}\text { Percentage } \\
(\%)\end{array}$ \\
\hline \multirow{3}{*}{ Age (years) } & $13-15$ & 156 & 41.1 \\
\hline & $16-19$ & 224 & 58.9 \\
\hline & $\mathrm{S} 1-\mathrm{S} 2$ & 61 & 16.1 \\
\hline \multirow[t]{3}{*}{ Class } & S3-S4 & 186 & 48.9 \\
\hline & S5-S6 & 133 & 35.0 \\
\hline & Muganda & 188 & 49.5 \\
\hline \multirow{5}{*}{ Ethnicity } & Munyakole & 66 & 17.4 \\
\hline & Musoga & 56 & 14.7 \\
\hline & Others & 70 & 18.4 \\
\hline & Catholic & 87 & 22.9 \\
\hline & Anglican & 44 & 11.6 \\
\hline \multirow[t]{3}{*}{ Religion } & Muslim & 149 & 39.2 \\
\hline & Protestant & 66 & 17.4 \\
\hline & Others specify & 34 & 8.9 \\
\hline \multirow{5}{*}{$\begin{array}{l}\text { The person } \\
\text { living with } \\
\text { the girl }\end{array}$} & Both parents & 184 & 48.4 \\
\hline & Mother only & 95 & 25.0 \\
\hline & Father only & 41 & 10.8 \\
\hline & Others & 60 & 15.8 \\
\hline & Tertiary & 13 & 3.4 \\
\hline Levels of & Primary & 19 & 5.0 \\
\hline Education & Secondary & 182 & 47.9 \\
\hline of the care & No Formal Education & 89 & 23.4 \\
\hline \multirow[t]{3}{*}{ giver } & Don't Know & 48 & 12.6 \\
\hline & Others & 29 & 7.6 \\
\hline & Peasant farmer & 36 & 9.5 \\
\hline Occupation & Employed/service & 142 & 37.4 \\
\hline of the & Business & 150 & 39.5 \\
\hline caregiver & Others & 52 & 13.7 \\
\hline Current re- & Not in any relationship & 216 & 56.8 \\
\hline lationship & Having a boy friend & 158 & 41.6 \\
\hline status & Cohabiting & 6 & 1.6 \\
\hline Types of & Nuclear & 217 & 57.1 \\
\hline family of & Extended & 163 & 42.9 \\
\hline tioealespon- & & 380100 & \\
\hline
\end{tabular}

\section{Individual factors affecting HPV Vaccination Uptake among adolescent girls}

This section presents findings of the study in relation to factors that affects HPV vaccination uptake among in-school adolescent girls in Wakiso district. The response was summarized and presented in table.

\section{Individual factors affecting HPV vaccination}

$\mathrm{X}^{2}=$ chi-square, $\mathrm{df}=$ degree of freedom, $\mathrm{p}$-value= level of significance $(<0.05)$

In Table, it shows the results of bivariate analyses for factors associated with participation in HPV vaccination. In the bivariate analyses, five factors were shown to be statistically significant with a $\mathrm{P}<0.05$, implying that these factors were associated with HPV vaccination. They included occupation of the caretaker $\left(X^{2}(3)=16.177^{a}, p=0.01\right)$, education level of the caretaker $\left(X^{2}(5)=21.144^{a}, p=0.01\right)$, perceived 
Table 4. shows uptake of HPV Vaccination among in-school adolescent girls

\begin{tabular}{|c|c|c|c|c|}
\hline & $\begin{array}{l}\text { Have you ever re- } \\
\text { ceived the HPV vac- } \\
\text { cine }\end{array}$ & $\begin{array}{l}\text { Number } \\
\text { of doses } \\
\text { received } \\
\text { if you had } \\
\text { received } \\
\text { the vaccine }\end{array}$ & & \\
\hline \multirow[t]{2}{*}{ Category } & Attributes & Yes & Two (\%) & \\
\hline & & $\begin{array}{l}\mathrm{No}(\%) \\
(\%)\end{array}$ & $\begin{array}{l}\text { One } \\
(\%)\end{array}$ & \\
\hline \multirow[t]{3}{*}{ Age (years) } & $13-15$ & $\begin{array}{l}1451 \\
(92(\nexists) 1)\end{array}$ & $8(34.8)$ & $\begin{array}{l}3 \\
(25)\end{array}$ \\
\hline & $16-19$ & $\begin{array}{l}2004(10 \\
(89.3)\end{array}$ & $.75(65.2)$ & $\begin{array}{l}19 \\
(75)\end{array}$ \\
\hline & Muganda & $\begin{array}{l}1744 \\
(92(\overline{6}) 4)\end{array}$ & $10(43.5)$ & $\begin{array}{l}4 \\
(33.3)\end{array}$ \\
\hline \multirow[t]{4}{*}{ Ethnicity } & Munyakole & $\begin{array}{l}579 \\
(86(4 B .6)\end{array}$ & $6(26.1)$ & $\begin{array}{l}3 \\
(25)\end{array}$ \\
\hline & Musoga & $\begin{array}{l}524 \\
(92(\nexists) 1)\end{array}$ & $3(13)$ & $\begin{array}{l}1 \\
(8.3)\end{array}$ \\
\hline & Others & $\begin{array}{l}628 \\
(88(.6) .4)\end{array}$ & $4(17.4)$ & $\begin{array}{l}4 \\
(33.3)\end{array}$ \\
\hline & Catholic & $\begin{array}{l}7710(11 \\
(88.5)\end{array}$ & $. \bar{B})(30.4)$ & $\begin{array}{l}3 \\
(25)\end{array}$ \\
\hline \multirow[t]{4}{*}{ Religion } & Anglican & $\begin{array}{l}422 \\
(95(9) 5)\end{array}$ & $2(8.7)$ & 0 \\
\hline & Muslim & $\begin{array}{l}1363 \\
(91(8,7)\end{array}$ & $9(39.1)$ & $\begin{array}{l}4 \\
(33.3)\end{array}$ \\
\hline & Protestant & $\begin{array}{l}597 \\
(89(410.6)\end{array}$ & $5(21.7)$ & $\begin{array}{l}2 \\
(16.7)\end{array}$ \\
\hline & Others specify & $\begin{array}{l}313(8.8) \\
(91.2)\end{array}$ & & $\begin{array}{l}3 \\
(25)\end{array}$ \\
\hline \multirow{5}{*}{$\begin{array}{l}\text { The person living } \\
\text { with the girl }\end{array}$} & Both parents & $\begin{array}{l}16815 \\
(91(8,2)\end{array}$ & $8(34.8)$ & $\begin{array}{l}7 \\
(58.3)\end{array}$ \\
\hline & Mother only & $\begin{array}{l}869 \\
(90(.9 .5)\end{array}$ & 7 (30.4) & $\begin{array}{l}2 \\
(16.7)\end{array}$ \\
\hline & Father only & $\begin{array}{l}410 \\
(10(\oplus))\end{array}$ & 0 & 0 \\
\hline & Others & $\begin{array}{l}5911 \\
(82018)\end{array}$ & $8(34.8)$ & $\begin{array}{l}3 \\
(25)\end{array}$ \\
\hline & Tertiary & $\begin{array}{l}7910(11 \\
(88.8)\end{array}$ & (1)(17.4) & $\begin{array}{l}10 \\
(50)\end{array}$ \\
\hline \multirow[t]{6}{*}{$\begin{array}{l}\text { Levels of Education } \\
\text { of the care giver }\end{array}$} & Primary & $\begin{array}{l}190 \\
(10(\mathbb{Q}))\end{array}$ & 0 & 0 \\
\hline & Secondary & $\begin{array}{l}1711 \\
(9406)\end{array}$ & $11(47.8)$ & 0 \\
\hline & No Formal Education & $\begin{array}{l}121 \\
(92(z) 7)\end{array}$ & $1(4.3)$ & 0 \\
\hline & Don't Know & $\begin{array}{l}444 \\
(91(8) 3)\end{array}$ & $4(17.4)$ & 0 \\
\hline & Others & $\begin{array}{l}209 \\
(69031)\end{array}$ & $3(13)$ & $\begin{array}{l}6 \\
(50)\end{array}$ \\
\hline & \multicolumn{3}{|c|}{$(10(0))$} & 0 \\
\hline $\begin{array}{l}\text { Occupation of the } \\
\text { caregiver }\end{array}$ & Employed/service & \multicolumn{2}{|c|}{$1221(14.85(65.2)$} & 6 \\
\hline
\end{tabular}


Table 5. shows Individual factors affecting HPV vaccination

HPV vaccination

Socio-demographics factors

Age (years)

Class

Ethnicity

The person living with the girl

Education of caretaker

$13-$
15
$16-$
19

54 (15.7) 175 (50.7) 116 (33.6)

S2

S3-

S4

S5-

56

$$
\text { No }(n=345) N(\%)
$$

Mugand§74 (50.4) 57 (16.5) 52 (15.1) 62 (18)

Mun-

yakole

Mu-

soga

Oth-

ers

Catholic77 (22.3) 42 (12.2) 136 (39.4) 59 (17.1) 31

An-

gli-

can

Mus-

lim

Protes-

tant

Oth-

ers

spec-

ify

Both $168(48.7) 86(24.9) 41$ (11.9) 59 (14.5)

par-

ents

Mother

only

Fa-

ther

only

Oth-

ers

Tertiary 79 (22.9) 19 (5.5) 171 (49.6) 12 (3.5) 44 Pri-

(12.8) 20 (5.8)

mary

Sec-

ondary

No

For-

mal

Ed-

uca-

\section{Yeschi-square df $P$ - $\left(n=\right.$ Bess)t $\left(X^{2}\right)$ value}

$\mathrm{N}$

(\%)

$\begin{array}{lll}111.476^{a} & 1 & .224 \\ (31.4) & & \\ 24 & & \\ (68.6) & & \\ 76.434^{a} & 2 & .040\end{array}$

(20)

10

(28.6)

18

(51.4)

$142.944^{a}$

(40)

9

(26.7)

4

(11.4)

8

(22.9)

$101.890^{a}$

(28.6)

2

(5.7)

13

(37.1)

7

(20)

3

(8.6)

$1510.070^{a}$

(42.9)

9

(25.7)

0

11

(31.4)

$1021.144^{a}$
$(28.6)$
0
11
$(31.4)$
1
$(2.9)$
4
$(11.4)$
9


susceptibility to HPV infections and cervical cancer $\left(X^{2}(1)=9.987^{a}, p=0.002\right)$, perceived benefits of HPV vaccination $\left(X^{2}(1)=8.962^{a}, p=0.03\right)$, and knowledge attributes regarding HPV and HPV infections $\left(X^{2}(1), p\right.$ $=0.00$ ) see table 4.3 above.

Community factors affecting HPV Vaccination Uptake among adolescent girls

Generally, the researcher first assessed if the mothers had had any idea or knowledge about HPV vaccination, and some respondents were able to elaborate as follows:

On 1st /07/2018, mothers in Kanyanya cell, Makindye-ssabagabo sub-county stated that;

[...]... HPV vaccination is a new word", the same applies to me....." I know, it is this kind of vaccine which was given to us for hepatitis... and later on, it was announced that it was expired."

This shows that the concept of HPV vaccination was not widely spread among respondents and many did not know what it was all about. However, some respondents got to know about it when discussed in the context of cervical cancer.

[...].. I heard about that vaccination being advertised on the radio but it was only once. I don't much about it" (mother from Katabi sub-county).

Much as the concept of HPV vaccination was gotten, some respondents from the selected sub-counties didn't have clear information about it as expressed in their views:

[...]...For me, I heard about that vaccination but I didn't really understand what it was all about, immunizing our girls........then cancer of the cervix...... I failed to connect the two statements... message was sketchy"(participant from Lugga Zone B, Makindye Ssabagabbo sub-county). At my child's school at Nakassero primary, I was told that our children are going to be vaccinated against cervical cancer...... that doctors are going to come at school so if we wish to be available at the vaccination time you can come............but I didn't understand much about it.... was it for family planning?........"(Participant from Entebbe sub-county, Division A, 9TH/07/2018),

\section{Perceived benefits of vaccination of young girls against HPV}

Based on the message from community members concerning HPV vaccination, HPV vaccination was not understood as many participants claimed to be their first time to hear about it. Those who had ever heard about HPV vaccination (immunization of young girls) understood it to prevent cervical cancer which itself was perceived to be a severe disease that had no cure. Mothers thought that vaccination only prevented cancer of the cervix and thus mentioned cervical cancer as being a serious disease once tested positive you done.

[...]...We have heard that once you are tested and found with cervical cancer, the doctors cut the infected area or remove the uterus because if they don't do that even other parts will be infected. If such important parts are removed what happens? ..........so if there is a way this can be avoided, why could we refuse to go for it?... we are hearing about this immunization for the first time. (participants from Kyengera, Mugoggo, Nsangi sub-county-Busiro North constituency, 20th/07/2018).

It was acknowledged that HPV vaccination was more likely to save resources that would be spent on caring for patients who might suffer from cervical cancer in the future. These perceptions influenced their attitudes toward vaccination.

[...].... Haaa, if the vaccines are there that can prevent cervical cancer, then that is very good. Having someone with that disease, you run bankrupt all the time looking for money for treatment, and yet the patient will also fail to survive. Even the government itself finds a big challenge in purchasing these drugs. We used to hear about the cancer machine which was being brought in the country and the government was struggling to raise money for that..... it had almost failed to pay taxes for it until supported by some people. So if the vaccines are available, that is good. That means our daughters will not get such diseases in the future. (Mothers from Milimu zone, Makindye-Ssabagabo, 4th /07/2018).

\section{Perceived cues to action on HPV vaccination}

Mothers expected that HPV vaccination will bring about the same positive changes in relation to cervical cancer. Mothers who had positive experiences with other childhood vaccinations considered HPV vaccination as safe as other vaccinations.

[....]....we have a feeling that even this vaccination is safe for our children. Compared to recent years when they had started immunizing against polio, many parents were scared of the vaccines because of the side effects 
which were noticed earlier. But these days at least everything is improved. It is even rare to hear someone with polio. I know if we also give it time as we take our children for vaccination we will have no more cancer cases in the future (participants from Kyengera, Mugoggo, Nsangi sub-county-Busiro North constituency, 20th/07/2018).

Nearly all those interviewed in the study indicated no major complaints or side effects being reported on HPV vaccination despite the fact that many mothers in nearly all interviews reported at least one negative experience from other vaccinations. These include pain in the vaccinated arm after injection, fever, swollen arm, or thighs among others. However, the participants reported the negative experiences as being mild and short term although this brought about the discontinuation of the immunization of the rest of the series to the minority mothers.

[...]...... when my son got that swelling and persistent pain, my husband refused me to ever take his son for any other immunization. Because when we went to the hospital we were told that the injection was administered in the wrong position that's why that happened..... (Participant from Lugga zone B, 6th/07/2018)

In relation to the findings from the group dialogue sessions, results in the table above reveal that perceived barriers to HPV vaccination among adolescent girls were not statistically significant $(P=0.197)$. These findings imply that, though there are some side effects associated with HPV vaccination, it is important to acknowledge that they have no effect on HPV vaccination uptake.

\section{Potential barriers to vaccination}

Some parents/mothers having got to know HPV vaccination during the group dialogue sessions, however, remained uncertain about the effectiveness of the vaccination in preventing HPV infection and cervical cancer. Mothers in two of the group dialogue sessions in held Nsangi sub-county and Makindye-Ssabagabo sub-county however questioned that;

[...].... How sure are we that our daughters will not suffer from HPV and cervical cancer after being immunized?...

While mothers in the community were complaining of the ages at which the vaccines are administered being too early, some of them were worried about their daughters who did not get vaccinated and their above 13 years.

[....]......Hmmm, those years are too early, I can't talk to my young girl about such drugs related to sexual activity, how can I start explaining it her that it is for future protection.... at least it would have been 15 years... (respondent from group dialogue session held in Katabi sub-county)

Contrary to some respondent's views, other members in the group responded indicating the unseriousness of some mothers, they urged that;

[...].....actually, if it was possible this new vaccine would be given to these girls as early as possible, like at two years.... Those who have children 14 years and above, our daughters are at risk but we have no option because we were not aware of the service. Cancer is like HIV, you take drugs for the rest of your life..... Some of you are joking about these diseases (Katabi town council -Katabi sub-county).

One parent disclosed a belief that vaccines in general are meant to infect them with the viruses so that they can die earlier. This mother mentioned Ugandans as being used for experiments. She mentioned that;

[....]... These whites think that Ugandans do not understand, they use us for testing their viruses, some time back we didn't have influenza...... and they started by saying new vaccine for preventing it, now it's everywhere and they have also failed to come up with proper medication for it. This means that there also testing if the virus for cervical cancer will work to help them sweep away Ugandans....(participant from Makindye-Ssabagabo sub-county, Milimu zone)

Summary findings

This chapter has presented results and findings based on data collected from the field. The HPV vaccination uptake rate among the in-school adolescent girls in the Wakiso district was low at 9.2\% (35/380). A number of modifiable factors related to HPV vaccination were identified which provides specific targets for interventions. 


\section{DISCUSSION, LIMITATION, CONCLUSION, AND RECOMMENDATION}

The HPV vaccination uptake rate among in-school adolescent girls in Wakiso district.

The present study provides information on the participation of HPV vaccination and the associated factors among in-school adolescent girls aged 13-19 years since the FDA approval of Gardasil for the prevention of genital warts and cervical cancer in Wakiso district central Uganda.

In this study, only $9.2 \%$ of the respondents had received at least one dose of the vaccine. The current results show the participation rate in the Wakiso district is much lower than the $80 \%$ national HPV vaccine coverage target.

The estimated uptake in this survey is lower than what the district reported for HPV vaccination uptake of $42 \%$. The low uptake of the HPV vaccine may also be attributed to inadequate training of health workers and limited funding from the central government.

However, studies that looked at uptake in low and middle-income countries revealed that human resources for health were inadequate for HPV vaccine delivery (Nabirye, 2020).

The individual Factors affecting HPV vaccination uptake among in-school adolescent girls in Wakiso district.

According to the Health Belief Model, susceptibility, severity, and benefits should be positively associated with screening, while barriers should be negatively associated. In this study, perceived barrier and severity were negatively associated with HPV vaccination which is in line with some previous studies (Kim et al., 2018). But susceptibility was positively associated with HPV vaccination which is opposite to the theory-predicted direction of the relation. It is possible that those respondents who had been vaccinated might have increased their perception about this susceptibility "HPV is a common STI" because they felt that vaccination would protect them from such HPV infections and hence they were unlikely to have genital warts and cervical cancer in the long run.

Furthermore, the results showed that the severity of cervical cancer and perceived barriers to HPV vaccine were not associated with HPV vaccination. It might be possible that other factors such as knowledge, occupation, and education level of the caretakers might have hindered their action to HPV vaccination. The findings on the relationship between HBM constructs and HPV vaccination were mixed in the literature: some studies reported null relations to be significantly associated with vaccine uptake after adjusting demographic characteristics. However, results in table 4.2, show that most respondents who had taken the vaccination lived with both parents (15/35), and for those who lived with their father's none had taken up the vaccination. However, it is not surprising given that most strategies involve women only.

Through the in-depth interviews in the group dialogue sessions, the study reveals that mothers who had ever heard about HPV vaccination or vaccination of young girls had no clear information concerning its administration like when to be given, number of doses, where to get the vaccine among others.

Similar results concerning low knowledge observed in this study are in line with other published studies in SSA ( Mupandawana et al., 2016). Therefore, it is necessary to develop HPV related educational opportunities for adolescent girls in the Wakiso district, particularly those attending schools or university in Wakiso district is necessary. Social workers in healthcare settings can utilize knowledge gained from this study to inform adolescent girls of the prevalence, transmission, and negative outcomes related to HPV. Although this study examined a specific population, it is imperative that all adolescent girls receive HPV and HPV vaccination information.

For that note, therefore, a single-time educational session may not be sufficient for knowledge translation among adolescent girls and their caregivers, and therefore continuous appropriate education programs for all caretakers and guardians about HPV, HPV vaccine, and cervical cancer are needed. Knowledge of HPV and HPV vaccine among the study subjects was indeed very poor. However, a few participants in the two cadres got to understand HPV when linked to cervical cancer, though many could not understand the causal link between HPV and cervical cancer.

Finally, the study found out that almost all study participants were willing to learn more about HPV and many asked questions about HPV, its transmission, and the likely consequences if contracted. 


\section{Community Factors that Affect HPV vaccination Uptake}

The results of this study indicate that mothers expressed low knowledge levels regarding HPV and HPV vaccination, and greater intention to accept the HPV vaccination. However, intention and uptake do not always translate over to actual HPV vaccination uptake. A recent study found that although $80 \%$ of non-Hispanic Black mothers between the ages of 18-34 years were aware of HPV, only 8\% actually received and advised their daughters to use or take up the HPV vaccine (Holman, 2013).

The study indicated that the actual use of the HPV vaccine among adolescent girls in the Wakiso district is low due to low knowledge about the vaccine and its availability. Additionally, most girls in this study stated that they received HPV information from their mothers. This was a disconcerting finding considering the low knowledge scores of participants. The origin of this disconnect may be due to miss communication or low health literacy and comprehension of HPV information during physician or health care visits with this population.

The findings indicate that community perceptions on HPV being associated with sexual activities may influence early sexual debut among adolescents. On the other hand, many of the women from this survey thought that sharing information related to sexuality would be shameful.

Another issue concerning knowledge was the misconception that you did not need to undergo screening if you had taken the HPV-vaccine. A study conducted in the UK three years after the vaccine-introduction among parents of these girls revealed that these parents did not know that screening would be needed irrespective of vaccination status.

\section{Limitations}

There are several limitations to consider with this study. First, the results are limited by the crosssectional design that causal inferences of the findings cannot be made. Second, the questionnaire adopted the Health Belief Model to explore the health beliefs and perceptions that influenced one's decision-making of HPV vaccination but the social factors that may influence the adolescent girl's choice were not explored. Lastly, the instrument was modified from a survey which was limited in reliability and validity. Future HPV related research would benefit from an instrument that was psychometrically sound.

\section{Conclusions}

The current findings highlight the importance of promoting HPV vaccination in preventing cervical cancer in this high-risk group in Uganda. The study showed that the HPV vaccination rate is suboptimal and that knowledge about HPV, cervical cancer and the HPV vaccine, benefits of the vaccine, and two susceptibility issues HPV infections, seem to be important factors in the promotion of vaccination among adolescent girls in Wakiso district central Uganda. The current study extends research in health promotion to a specific population of adolescents who are attending secondary school education and caretakers who are engaged in several businesses across the country. With this information, health policy planners can play a more active role in making recommendations for HPV vaccination by providing more appropriate target programs and policies in promoting HPV vaccination to this particular group of young women.

\section{Recommendation}

To increase HPV awareness, knowledge, and ultimately HPV vaccine uptake, it is vital to include Adolescent girls in research pertaining to HPV and cancer prevention research. It is through this work that social workers can ensure that culturally specific barriers are identified, health disparities are addressed and appropriate interventions are implemented.

There is further a need to offer ample orientation and training to all health workers about disseminating information on HPV vaccination to all eligible adolescents and their caretakers. By providing training to health workers or service providers; attention should be given to the unique challenges including the severity and future burden of HPV infections and HPV-related cancers.

From the community level, it is also appropriate to bring to the parents' attention the challenges their adolescent children face if contracted with HPV infection such as genital warts so as to open up a dialogue with the immediate significant others. The focus should be geared towards increasing knowledge and awareness of HPV infections and the purpose of HPV vaccination to all parents and caregivers. 
It would be meaningful to fully engage young people or in particular older adolescents (16-19 years) in decision making so as to give their views concerning their sexual health in regard to up taking the available health service needs as a means of giving adolescents a voice.

Community representatives should be involved in creating awareness to the people of their areas as well as the use of celebrities in health messages may also be beneficial.

Lastly, children (young girls targeted for this study) should be informed of the kind of vaccine administered to let them know what they are for.

\section{Areas of Future Studies}

Based on the study findings there is a need to conduct a study on the relevance of Healthcare professionals in promoting HPV vaccination among the in-school younger adolescents in Uganda. Assessment of health system factors affecting uptake of the HPV vaccine and HPV related research within the population (adolescents girls) is needed to further advance the development of knowledge and inform social work practice, behaviour therapy, counselling, clinical practice, community practice, as well as the evaluation of social policies.

\section{ACKNOWLEDGEMENT}

Let me take this opportunity to first of all thank the almighty God for giving me the strength, wisdom, and competence to successfully complete this program.

My humble appreciation goes to Faculty of Health Sciences and the management of Uganda Martyrs University for giving me the special opportunity to pursue my academic dream of being a public health specialist. The environment was very conducive for me to achieve this dream. Allow me in a special way to thank all lecturers in their different capacities for the continuous and tireless support they offered during my stay in Uganda Martyrs University, not forgetting my classmates, friends, non teaching staff, and the community of Nkozi who made my stay as conducive as possible.

Essentially, it would, indeed, be a mockery of own best intentions if I do not recognize the role of my supervisor, mentor, and lecturer Dr. Miisa Nanyingi for her academic guidance and advice at all stages of my work. She made the entire study possible. Without her technical support, this report would not be in this shape. I also thank my colleague Miss Rebecca Ariokot for the constant enrichment of knowledge especially in data analysis and presentation that she always offered when consulted.

Special and heartfelt thanks goes to all my colleagues and also my relatives who were always by my side both psychologically and financially, not forgetting my dear husband Dr. Sulaiman Mahmood Kakooza whose continuous encouragement and financial support have kept me progressive throughout my studies.

My unforgettable appreciation goes to Mr. Kizito Muwonge and Dr Kiyingi Frank Pio of the University of Kisubi (Unik) whose continuous mentorship has kept me moving forward in the academic arena.

Finally, I am passionately grateful to all those whom I may not have mentioned here but contributed in one way or the other towards the success of this work. May God Bless you all.

\section{ACRYNOMS AND ABBREVIATIONS}

ACIP : Advisory Committee on Immunization Practices

ADC : Adeno- and adenosquamous-carcinoma

AIDS : Acquired immunodeficiency syndrome

CDP : Child Days Plus

HBM : Health Belief Model

HCP : Health Care Professionals

HIV : Human immunodeficiency virus

HPV : Human Papilloma Virus

HSSP II : Health Sector Strategic Plan II

IARC : International Agency for Research on Cancer

ICC : Invasive Cervical Cancer

LDCs : Low Developing Countries.

LMICs : Low-and Middle Income countries

$\mathrm{MOH}$ : Ministry of Health

NPHC : National Population and Housing Census 
$\mathrm{RH}$ : Reproductive health

SSA : Sub Saharan Africa

STD : Sexually Transmitted Diseases

STI : Sexually Transmitted Infection

UNEPI : Uganda National Expanded Program on Immunization

WHO : World Health Organization

2VHPV : HPV bivalent vaccine

\section{References:}

1. Agnes Binagwaho., Fidele Ngabo., Claire M Wagner., Cathy Mugeni., Maurice Gatera., Cameron T Nutt., \& Sabin Nsanzimana. (2013). Integration of comprehensive women's health programmes into health systems: cervical cancer prevention, care and control in Rwanda. Bulletin of the World Health Organization, 91(9):697-703.

2. Allison Bingham., Jennifer Kidwell Drake., \& D. Scott LaMontagne. (2009). Sociocultural Issues in the Introduction of Human Papillomavirus Vaccine in Low-Resource Settings. Archives of Pediatrics \& Adolescent Medicine, 163(5):455-455.

3. Amanda F. Dempsey., Leah M. Abraham., Vanessa Dalton., \& Mack Ruffin. (2009). Understanding the Reasons Why Mothers Do or Do Not Have Their Adolescent Daughters Vaccinated Against Human Papillomavirus. Annals of Epidemiology, 19(8):531-538.

4. AneelaN Hussain., Abdullah Alkhenizan., Patricia McWalter., Nusrat Qazi., Amal Alshmassi., Samina Farooqi., \& Ahmed Abdulkarim. (2016). Attitudes and perceptions towards HPV vaccination among young women in Saudi Arabia. Journal of Family and Community Medicine, 23(3):145-145.

5. Anna W. LaVigne., Scott A. Triedman., Thomas C. Randall., Edward L. Trimble., \& Akila N. Viswanathan. (2017). Cervical cancer in low and middle income countries: Addressing barriers to radiotherapy delivery. Gynecologic Oncology Reports, 22:16-20.

6. Carolyn Nakisige., Melissa Schwartz., \& Anthony Okoth Ndira. (2007). Cervical cancer screening and treatment in Uganda. Gynecologic Oncology Reports, 20:37-40

7. Cayce $C$ Hughes., Amanda L Jones., Kristen A Feemster., \& Alexander G Fiks. (2011). HPV vaccine decision making in pediatric primary care: a semi-structured interview study. BMC Pediatrics, 11(1):74-83.

8. Cecily Banura., Florence M Mirembe., Anne R Katahoire., Proscovia B Namujju., \& Edward K Mbidde. (2012). Universal routine HPV vaccination for young girls in Uganda: a review of opportunities and potential obstacles. Infectious Agents and Cancer, 7(1)

9. Christian Chigozie Makwe., Rose Ihuoma Anorlu., \& Kofoworola Abimbola Odeyemi. (2012). Human papillomavirus (HPV) infection and vaccines: Knowledge, attitude and perception among female students at the University of Lagos, Lagos, Nigeria. Journal of Epidemiology and Global Health, 2(4):199-199.

10. D S Lamontagne., S Barge., N Thi Le., E Mugisha., M E Penny., S Gandhi., A Janmohamed., E Kumakech., N R Mosqueira., N Q Nguyen., P Paul., Y Tang., T H Minh., B P Uttekar., \& A O Jumaan. (2011) Human papillomavirus vaccine delivery strategies that achieved high coverage in low- and middle-income countries. Bull. World Health Organ, 89:821-830, 2011.

11. Dalan S. Read., Michael A. Joseph., Veronika Polishchuk., \& Amy L. Suss. (2010). Attitudes and Perceptions of the HPV Vaccine in Caribbean and African-American Adolescent Girls and their Parents. Journal of Pediatric and Adolescent Gynecology, 23(4):242-245

12. Dawn M. Holman., Vicki Benard., Katherine B. Roland., Meg Watson., Nicole Liddon., \& Shannon Stokley.(2014). Barriers to Human Papillomavirus Vaccination Among US Adolescents. JAMA Pediatrics, 168(1):76-76.

13. Edith T. Mupandawana \& Ruth Cross. (2016). Attitudes towards human papillomavirus vaccination among African parents in a city in the north of England: a qualitative study. Reproductive Health, 13(1).

14. Human Papillomavirus Vaccination: Recommendations of the Advisory Committee on Immunization Practices (ACIP). (2014), CDC 
15. Isaac Okoth Randa. (2016). Integrated Model of Affordable Housing Delivery for the City of Windhoek.

16. J Kim. (2018). The Relationship of Health Beliefs with Information Sources and HPV Vaccine Acceptance among Young Adults in Korea. International journal of environmental research and public health, 15(4).

17. Juliet Nabirye., Livex Andrew Okwi., Rebecca Nuwematsiko., George Kiwanuka., Fiston Muneza., Carol Kamya., \& Juliet N. Babirye.(2020) Health system factors influencing uptake of Human Papilloma Virus (HPV) vaccine among adolescent girls 9-15 years in Mbale District, Uganda. BMC Public Health, 20(1):171-17

18. K P Braaten \& M R Laufer. (2008). Human Papillomavirus (HPV), HPV-Related Disease, and the HPV Vaccine. Top of Form, 2008.

19. Lauri E. Markowitz., Vivien Tsu., Shelley L. Deeks., Heather Cubie., Susan A. Wang., Andrea S. Vicari., \& Julia M.L. Brotherton. (2012). Human Papillomavirus Vaccine Introduction - The First Five Years.

20. Lisa Rambout., Mariam Tashkandi., Laura Hopkins., \& Andrea C. Tricco. (2014). Self-reported barriers and facilitators to preventive human papillomavirus vaccination among adolescent girls and young women: A systematic review. Preventive Medicine, 58:22-32.

21. M L Small. (2011). How to Conduct a Mixed Methods Study: Recent Trends in a Rapidly Growing Literature. Annual Review of Sociology, 37:57-86.

22. M. M. Berger., H. Mairbäurl., C. Dehnert., E. Swenson., \&. Bärtsch. (2010) Transpulmonary plasma catecholamines in acute high altitude pulmonary hypertension, volume 27. Ovid Technologies (Wolters Kluwer Health), Berlin, Germany; Hum VaccinImmunother 9

23. Richard G. Wamai., Claudine Akono Ayissi., Geofrey O. Oduwo., Stacey Perlman., Edith Welty., Simon Manga., \& Javier Gordon Ogembo. (2012). Assessing the Effectiveness of a Community-Based Sensitization Strategy in Creating Awareness About HPV, Cervical Cancer and HPV Vaccine Among Parents in North West Cameroon. Journal of Community Health, 37(5):917-926.

24. S Sudman \& N M Bradburn. (1982). Askinq Questions. Josey-Bass Inc. Publishers, San Francisco.

25. Sharon J.M. Kessels., Helen S. Marshall., Maureen Watson., Annette J. Braunack-Mayer., Rob Reuzel., \& Rebecca L. Tooher. (2012) Factors associated with HPV vaccine uptake in teenage girls: A systematic review. Vaccine, 30(24):3546-3556

26. Stacey Perlman., Richard G. Wamai., Paul A. Bain., Thomas Welty., Edith Welty., \& Javier Gordon Ogembo. (2014) Knowledge and Awareness of HPV Vaccine and Acceptability to Vaccinate in Sub-Saharan Africa: A Systematic Review. PLoS ONE, 9(3):e90912-e90912, 2014.

27. Tom Glass Hopkins \& Nick Wood. (2013) Female human papillomavirus (HPV) vaccination: Global uptake and the impact of attitudes. Vaccine, 31(13):1673-1679. 